\title{
Other relevant components of nuts: phytosterols, folate and minerals
}

\author{
Ramon Segura $^{1 *}$, Casimiro Javierre ${ }^{1}, \mathrm{M}^{\mathrm{a}}$ Antonia Lizarraga ${ }^{1}$ and Emilio Ros ${ }^{2}$ \\ ${ }^{1}$ Department of Physiological Sciences II, Faculty of Medicine, IDIBELL, University of Barcelona, Barcelona, Spain \\ ${ }^{2}$ Lipid Clinic, Hospital Clínic, IDIBAPS, Barcelona, Spain
}

\begin{abstract}
Nuts contain significant amounts of essential micronutrients that are associated with an improved health status when consumed at doses beyond those necessary to prevent deficiency states. Nuts do not contain cholesterol, but they are rich in chemically related phytosterols, a class of compounds that interfere with intestinal cholesterol absorption and thus help lower blood cholesterol. Nuts also contain folate, a B-vitamin necessary for normal cellular function that plays an important role in detoxifying homocysteine, a sulphur-containing amino acid with atherothrombotic properties that accumulates in plasma when folate status is subnormal. Compared to other common foodstuffs, nuts have an optimal nutritional density with respect to healthy minerals, such as calcium, magnesium and potassium. Like that of most vegetables, the sodium content of nuts is very low. A high intake of calcium, magnesium and potassium, together with a low sodium intake, is associated with protection against bone demineralisation, arterial hypertension, insulin resistance, and overall cardiovascular risk. Phytosterols might justify part of the cholesterol-lowering effect of nut intake beyond that attributable to fatty acid exchange, while the mineral richness of nuts probably contributes to the prevention of diabetes and coronary heart disease observed in epidemiological studies in association with frequent nut consumption.
\end{abstract}

Nuts: Phytosterols: Folate: Calcium: Magnesium: Potassium: Sodium

In the not too distant past, nutritional epidemiology experts emphasized the adequate intake of macronutrients (sugars, starches, fibre, fatty acids and protein) and the importance of a balanced diet for good health. Less attention was usually paid to the intake of vitamins, minerals and other minor food components, the reason being that marked micronutrient deficiency has been a rarity in developed countries since the 1950s. However, the nutritional, cultural and physical activity patterns of affluent societies have led to a profound change in eating habits (including reduced intake of micronutrients) and energy expenditure that, in conjunction with a genetic background that is still fit for our hunter-gatherer ancestors but not for contemporary humans, underlie the current epidemic of coronary heart disease, obesity, diabetes and other so-called diseases of civilization (Cordain et al. 2005). On the other hand, there has been an increasing recognition that many micronutrients may have beneficial health effects when consumed in amounts beyond recommended allowances (Miller \& Anderson, 1999; Vaskonen, 2003; Stover, 2004; Nieves, 2005). Some non-nutritive food components (i.e. vegetable sterols) have also demonstrated favourable effects on intermediate markers of cardiovascular risk (Piironen et al. 2000; Ostlund, 2002).

Nuts contain small quantities of several bioactive compounds that are relevant to health. In this paper we will briefly describe the principal nutritional and functional characteristics of some of these components, namely phytosterols, folate and minerals.

\section{Phytosterols \\ Biochemistry}

Among the fatty fraction of nuts there are non-cholesterol sterols belonging to a heterogeneous group of compounds known as plant sterols or phytosterols (Piironen et al. 2000; Moreau et al. 2002). They are important structural components of plant membranes, where they serve to stabilize phospholipid bilayers just as cholesterol does in animal cell membranes (Hartmann, 1998). Like cholesterol, phytosterols are synthesized from acetyl coenzyme-A via squalene. Most phytosterols contain 28 or 29 carbons and one or two double bonds, typically one in the sterol nucleus and sometimes a second in the alkyl side chain. Saturated phytosterols (containing no double bonds) are called phytostanols and occur in trace levels only in most plants. In plant tissues, phytosterols may occur as free alcohols or as conjugates (fatty-acid esters, steryl glycosides or acylated steryl glycosides). In free phytosterols, the $3 \beta-\mathrm{OH}$ group on the A-ring of the sterol nucleus is underivatized, whereas in the conjugates the $\mathrm{OH}$ is covalently bound with another constituent (a fatty acid, a hexose moiety, most commonly glucose, or a 6-fatty-acyl hexose). More than 200 different types of phytosterols have been reported in plant species (Piironen et al. 2000; Moreau et al. 2002).

The chemical structure of phytosterols is very similar to that of cholesterol, except that the C-24 at the side-chain contains additional chemical groups. The trivial names of the phytosterols that are most abundant in plants are campesterol, 
$\beta$-sitosterol, 5-avenasterol and stigmasterol, and they differ from cholesterol by C-24 addition of a methyl group, an ethyl group, or an ethyldiene group, and a diene at C-22, respectively (Fig. 1).

\section{Food content}

The intake of phytosterols varies among different populations depending on dietary habits. The average Western diet is reported to contain $150-450 \mathrm{mg} / \mathrm{d}$ phytosterols (de Vries et al. 1997; Ostlund, 2002). Vegetarians, however, may consume up to $1 \mathrm{~g} / \mathrm{d}$ (Vuoristo \& Miettinen, 1994). Vegetable oils are the richest dietary sources of phytosterols. In addition, variable amounts are present in cereals, nuts, seeds, vegetables, fruits and berries (Piironen et al. 2000; Ostlund, 2002). On average, vegetable oils contain $150-500 \mathrm{mg}$ per $100 \mathrm{~g}$, while corn, rapeseed, rice bran and wheat germ oils contain higher amounts. Nuts contain relevant quantities, $\beta$-sitosterol being the most abundant. Table 1 shows the phytosterol content of nuts, as listed in two food composition sources, the USDA Database and the recent publication of Phillips et al. (2005), which generally provides greater concentrations than those reported in existing databases, probably due to the inclusion of steryl glycosides, which represent a significant portion of total sterols in nuts and are not usually measured.

\section{Intestinal cholesterol absorption}

Cholesterol homeostasis is maintained by balancing intestinal cholesterol absorption and endogenous cholesterol synthesis with biliary bile acid and cholesterol secretion (Dietschy et al. 1993). However, because bile acids are efficiently reabsorbed and a fraction of biliary cholesterol is absorbed in the intestine, the overall whole-body cholesterol balance is kept mainly by matching cholesterol synthesis with fecal sterol losses. The latter are strictly dependent on the efficiency of the intestinal absorption of cholesterol (both dietary and biliary), which in turn relates to blood cholesterol levels (Kesäniemi \& Miettinen, 1987), a reason why the regulation of cholesterol absorption has been studied extensively and is of growing interest as a target of interventions aimed at lowering blood cholesterol levels (Ros, 2000; Sudhop \& von Bergmann, 2002).

Cholesterol is always present in the intestine, originating from three sources: diet, bile and desquamated intestinal cells. Cholesterol intake varies with dietary habits, usually ranging between 150 and $400 \mathrm{mg} / \mathrm{d}$ in the Western diet. The mass of biliary cholesterol entering the duodenum daily averages $1000 \mathrm{mg}$ (Northfield \& Hoffman, 1975). Intestinal cholesterol from exfoliated enterocytes represents a sizeable amount, 300-400 mg/d (Vuoristo \& Miettinen, 1985). Important requirements for intestinal cholesterol absorption are hydrolysis of dietary cholesteryl esters, as only free cholesterol is suitable for absorption (Vahouny et al. 1964); the presence of bile salts to achieve adequate micellar solubilization; and reesterification by intestinal cells, a requisite for incorporation into chylomicrons and secretion into the circulation (Turley \& Dietschy, 2003). Cholesterol is transferred from mixed micelles into intestinal epithelial cells by a sterol transfer protein located in the brush border membrane, recently identified as Nieman-Pick C like 1 protein (Altmann et al. 2004). The enterocyte modulates the amount of cholesterol being absorbed by means of a reverse transport system, the ABCG5 and ABCG8 sterol transporters, also located in the apical membrane (Berge et al. 2000; Lee et al. 2001). Thus, cholesterol absorption is a complex process with many steps that are regulated by multiple genes and their protein products.

Cholesterol absorption efficiency is determined by the net effect of the bidirectional transport of cholesterol molecules across the apical membrane of intestinal cells. Several studies have shown that the gut absorbs on average less than $50 \%$ of the cholesterol mass present in the intestinal lumen, although a high interindividual variability exists, ranging from 20 to $80 \%$ (Sehayek et al. 1998; Bosner et al. 1999). The reasons for the variable efficiency of cholesterol absorption are not<smiles>[R]C1CCC2C3CC=C4CC(=O)CC[C@]4(C)C3CCC12C</smiles>

$\beta-$ Sitosterol

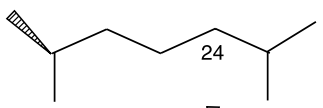<smiles>C=C(C)CCC(=O)C(C)CC</smiles><smiles>C=C(C)CC[C@H](C=CC)C(C)C</smiles><smiles>C=C(C)C=CC(=CC)C(C)C</smiles><smiles>C=C(C)CCC(=CC)C(C)C</smiles>

Fig. 1. Chemical structure of sterols, showing the side-chain $(R)$ of cholesterol and the most common phytosterols. 
Table 1. Phytosterol content of nuts in $\mathrm{mg} / 100 \mathrm{~g}$ edible portion

\begin{tabular}{|c|c|c|c|c|c|c|c|c|c|}
\hline Almonds & $111^{\mathrm{a}}$ & $143^{b}$ & 5 & 5 & 4 & 5 & $\frac{5 \text {-avenasterol }}{20^{\mathrm{b}}}$ & 120 & 199 \\
\hline Cashews & NR & 113 & NR & 9 & NR & 1 & 14 & 158 & 150 \\
\hline Hazelnuts & 89 & 102 & 6 & 7 & 1 & 2 & 3 & 96 & 121 \\
\hline Macadamia nuts & 108 & 144 & 8 & 10 & 0 & ND & 13 & 116 & 187 \\
\hline Pine nuts & NR & 132 & NR & 20 & NR & 1 & 40 & 141 & 236 \\
\hline Pistachios & 198 & 210 & 10 & 10 & 5 & 2 & 26 & 214 & 279 \\
\hline Walnuts & 64 & 89 & 7 & 5 & 1 & ND & 7 & 72 & 113 \\
\hline
\end{tabular}

Sources: aUS Department of Agriculture Nutrient Data Base at http://www.nal.usda.gov/fnic/cgi-bin/nut_search.pl Accessed 29 December 2005

${ }^{b}$ Phillips KM et al. (2005) J Agric Food Chem 53, 9436-9445.

completely understood. While there is increasing evidence that genetic variability at loci related with sterol transport affects cholesterol absorption (Sehayek, 2004), dietary factors also play a significant role. Among them, the amount of sterols in food is an important modulator of cholesterol absorption.

\section{Interference with cholesterol absorption by phytosterols}

It has been known for more than 50 years that phytosterols interfere with cholesterol absorption (Thompson \& Grundy, 2005), thus their presence in variable amounts in the usual diet may explain part of the variability in cholesterol absorption efficiency. The mechanism of action of phytosterols has been linked to their hydrophobicity, which is higher than cholesterol because of a bulkier hydrocarbon molecule (Fig. 1) and entails a higher affinity for micelles than has cholesterol. Consequently, cholesterol is displaced from micelles and the amount available for absorption is limited (Ostlund, 2002). Additional mechanisms are probably at work, because phytosterols are not confined to the intestinal lumen and, though much more inefficiently than cholesterol, are absorbed by the sterol transporter NPC1L1, undergo enterohepatic circulation, and are reexcreted by the same ABCG5/8 transporters that efflux cholesterol (von Bergmann et al. 2005). The net result is reduced intestinal absorption and less cholesterol reaching the liver via chylomicrons remnants. In response to the decreased supply of exogenous cholesterol, receptor-mediated uptake of lipoprotein cholesterol is enhanced and a reduction of the serum LDL cholesterol level ensues (Ros, 2000; Sudhop \& von Bergmann, 2002; Plat \& Mensink, 2005).

Phytosterols at pharmacological doses were used sparingly as cholesterol-lowering agents for several decades. More recently, their use has become widespread because newer formulations have allowed smaller doses to be incorporated into various functional foods that target elevated blood cholesterol with proven efficacy and are attractive adjuncts to dietary therapy. Meta-analyses of randomized controlled trials in which they have been used reveal an average $10 \%$ LDL cholesterol reduction at doses $\approx 2 \mathrm{~g} / \mathrm{d}$, the benefit being similar in different population groups (Law, 2000; Katan et al. 2003; O'Neill et al. 2005). An important question is whether phytosterols in natural, unsupplemented plant foods are also bioactive (Ostlund, 2004).

\section{Do phytosterols in natural foods lower blood cholesterol?}

As described, the phytosterol content of free-living diets ranges from 150 to $450 \mathrm{mg} / \mathrm{d}$, and may be more in recommended vegetable-rich diets. Baseline intake is not taken into consideration in clinical trials of phytosterol-supplemented foods, and the possibility exists that the cholesterol-lowering effect would be greater if the background diet was depleted in phytosterols, i.e. phytosterols in natural foods might help lower blood cholesterol. Recent work suggests that this hypothesis should be taken into consideration. Single meal studies with natural phytosterol-rich foods, such as corn oil and wheat germ muffins, have demonstrated $\mathrm{a} \approx 40 \%$ reduction of intestinal cholesterol absorption that reverts to baseline when the same foods are given after being depleted of phytosterols (Ostlund et al. 2002, 2003). In these studies, as little as $150 \mathrm{mg}$ phytosterols significantly reduced cholesterol absorption. Shin et al. (2005) also assessed cholesterol absorption after single meals supplemented with 200,300 or $500 \mathrm{mg}$ micellar phytosterols and found a reduction of $23-32 \%$ at the higher doses. These observations show that phytosterols may effectively reduce cholesterol absorption at very low doses. The fact that dietary phytosterol intake was inversely related to serum cholesterol in a large population cohort (Andersson et al. 2004) suggests that phytosterols in the usual diet do reduce cholesterol absorption.

The cholesterol-lowering efficacy of phytosterols and stanols is significantly higher when blended into a fat source, such as margarine, butter or vegetable oils, before administration (Jones et al. 1997). In contrast, when administered in powder form, plant stanols had no cholesterol-lowering effect (Denke, 1995). This suggests that the bioactivity of phytosterols is enhanced when they are emulsified into a fatty vehicle (Vanstone et al. 2002). In this context, it is relevant to signal that the high fat content of nut matrices should improve the bioactivity of the phytosterols therein contained.

The cholesterol-lowering efficacy of nut intake in feeding trials has often been higher than that predicted on the basis of fatty acid exchange (Griel \& Kris-Etherton, 2006). Phystosterols in nuts are likely to be responsible in part for this effect. 


\section{Folate}

Folate is a generic term for a complex family of water-soluble B-group vitamins that are found in many foodstuffs. The parent compound of folates is pteroic acid. Naturally occurring folates are mostly reduced tetrahydropteroylglutamates, often in polyglutamyl form and usually one-carbon substituted. Folic acid (pteroylmonoglutamic acid) is the synthetic form used in supplements and food fortification. A subgroup of tetrahydrofolates is the biologically most important one as it plays a crucial role in cellular function by actively participating in reactions involving the transfer of one-carbon moieties, such as methyl $\left(\mathrm{CH}_{3}\right)$ groups (Mason, 2003). Folates play an important role in nucleotide synthesis, methylation and gene expression. Examples are the synthesis of the amino acids methionine, serine and hystidine; the synthesis of thymidine, which is essential for the de novo construction or repair of DNA; the methylation of cytosine in DNA, which regulates gene expression; and the remethylation of plasma homocysteine to methionine (Shane, 1995; Stover, 2004).

Humans and other mammals are not able to synthesize folate and must obtain it from exogenous sources. This essential micronutrient is present in foods from both vegetable and animal origin. Offal (liver, kidney) is especially rich in folate, and green leafy vegetables, fruits, pulses, cereals, mushrooms and nuts are good plant sources (Freisleben et al. 2003). Table 2 shows the folate content of nuts and of other common foods for comparison. Because folates are labile molecules and are likely to be destroyed by heat or oxidation,

Table 2. Folate content of nuts and other foods ( $\mu \mathrm{g} / 100 \mathrm{~g}$ edible portion)

\begin{tabular}{|c|c|}
\hline Nuts & Total folate \\
\hline Almonds & 29 \\
\hline Brazil nuts & 22 \\
\hline Cashews & 25 \\
\hline Hazelnuts & 113 \\
\hline Macadamia nuts & 11 \\
\hline Peanuts & 240 \\
\hline Pecans & 22 \\
\hline Pistachios & 51 \\
\hline Walnuts & 98 \\
\hline \multicolumn{2}{|l|}{ Other foods } \\
\hline Apples (with skin) & 3 \\
\hline Asparagus (cooked) & 149 \\
\hline Bananas & 20 \\
\hline Beans (white, cooked) & 81 \\
\hline Beets (cooked) & 80 \\
\hline Broccoli (cooked) & 108 \\
\hline Cheese (cheddar) & 18 \\
\hline Chickpeas (cooked) & 172 \\
\hline Ham & 7 \\
\hline Lettuce (romaine) & 136 \\
\hline Milk & 5 \\
\hline Pears & 7 \\
\hline Rice (white, cooked) & 58 \\
\hline Sardines (canned in oil) & 12 \\
\hline Spinach (cooked) & 146 \\
\hline Tomato & 15 \\
\hline Veal (cooked) & 15 \\
\hline Wheat bread & 50 \\
\hline
\end{tabular}

food processing and cooking may cause losses of up to $90 \%$ or more when using high temperatures and large amounts of water which is discarded. Unlike synthetic folic acid supplements, naturally occurring folates have to be cleaved from their polyglutamate into a monoglutamate form by an intestinal brush border deconjugase before active, protein carrier-mediated absorption can take place (Said, 2004), a reason why the bioavailability of naturally occurring folates is incomplete, although human studies have shown a great variation, ranging anywhere between 10 and $98 \%$ (Sanderson et al. 2003; McNulty \& Pentieva, 2004).

The dietary reference intake (DRI) for adults (states of pregnancy and lactation excluded) of naturally occurring folate vitamins is now $400 \mu \mathrm{g}$ daily, an amount that doubles what was recently recommended to avoid folate deficiency. This recognizes that a suboptimal folate status may be implicated in the pathogenesis of several disorders in humans that can be prevented with appropriate folate intake from natural and/or fortified foods.

\section{Diseases associated with folate depletion or suboptimal folate status}

This vitamin has attracted major scientific and public health interest in recent years, not only because of the important health problems causally related to its deficiency, but also because a suboptimal folate status appears to be associated with an increased risk of several prevalent chronic diseases. First is the well-known relationship of overt folate deficiency to megaloblastic anaemia (a common problem in chronic alcoholism) and, particularly when occurring in pregnant women, to neural tube and other congenital defects in the newborn (MRC Vitamin Study Research Group, 1991; Czeizel \& Dudas, 1992). The latter was the main reason for mandatory folic acid fortification of all flour and uncooked cereal products in the United States, implemented in January 1998 (Food and Drug Administration, 1996). Second, there are increasing evidences for the potential role of suboptimal folate nutrition as a risk factor for cardiovascular diseases (Strain et al. 2004), certain cancers (Kim, 1999; Choi \& Mason, 2000) and neuro-psychiatric conditions (Seshadri et al. 2002; Prins et al. 2002). Indeed, when dietary intakes are considered from this perspective, rather than from the view of merely preventing overt folate deficiency, it is clear that a suboptimal folate status is quite frequent in the population.

A low folate status is clearly associated with an elevated plasma level of homocysteine (Hcy), a sulphur-containing amino acid and atherothrombotic molecule that requires folic acid as a cofactor to be remethylated into methionine (Welch \& Loscalzo, 1998). Dietary folate is the most important dietary determinant of blood Hcy concentrations (Selhub et al. 1993), and a substantial body of epidemiological evidence has accumulated in the last 30 years on the role of mild hyperhomocysteinemia (HHcy) in the development of coronary artery disease, stroke and deep vein thrombosis (The Homocysteine Studies Collaboration, 2002) (Wald et al. 2002).

The role of folate as an essential cofactor in purine synthesis explains why its deficiency in tissues with rapidly replicating neoplastic cells results in ineffective DNA production 
and inhibition of tumour growth (Kim, 1999; Choi \& Mason, 2002). Indeed, this has been the basis for cancer chemotherapy with antifolate agents such as methotrexate. Folate deficiency, however, appears to have the opposite effect in normal tissues, predisposing them to neoplastic transformation (Kim, 1999). The plausible mechanisms for this effect relate to the sole biochemical function known for folate (mediating the transfer of one-carbon moieties) and its role in DNA synthesis, integrity and repair.

A subnormal folate status might be a risk factor for cognitive decline and dementia through two mechanisms. First, a shortage of folic acid causes an increase in Hcy concentrations that have been associated with an increased prevalence of poor cognitive function (Prins et al. 2002) and an increased risk of development of Alzheimer disease (Seshadri et al. 2002). Second, low serum concentrations of folic acid might result in a reduced availability of methyl groups in the brain. This can ultimately result in the impaired formation of myelin, various neurotransmitters and membrane phospholipids. However, the latest evidences suggest that the association of high serum concentrations of Hcy and low folic acid with cognitive impairment in old age or other neuro-psychiatric conditions is likely to be a consequence of disease and not a contributory cause (Luchsinger \& Mayeux, 2004; Taylor et al. 2004; Mooijaart et al. 2005).

\section{Role of folate in disease prevention}

The reduction in incidence of neural tube defects by maternal use of supplemental folic acid is well established (MRC Vitamin Study Research Group, 1991; Czeizel \& Dudas, 1992). Decreasing rates of neural tube and other congenital defects after food fortification in the United States and Canada represent an important public health achievement, although there has been some concern about an increased incidence of multiple births and miscarriages (Bailey \& Berry, 2005). The effectiveness of the food fortification programme in the United States was clearly shown by Jacques et al. (1999). These authors reported that intake of cereal products fortified with folic acid $(140 \mu \mathrm{g} / 100 \mathrm{~g}$ of grain products) increased the serum folate concentration by more than two-fold, while practically abolishing the prevalence of folate deficiency and significantly reducing the frequency of HHcy (Jacques et al. 1999).

Indeed, HHcy represents a modifiable cardiovascular risk factor, since many studies have shown that folic acid along with vitamin B12 and B6 supplementation effectively lowers Hcy in a dose-dependent manner (Homocysteine Lowering Trialists' Collaboration, 2005). The maximum reduction $(23 \%)$ in plasma homocysteine concentration was observed with $0.8 \mathrm{mg}$ folic acid/d, with no further reduction at higher doses; 20 and $13 \%$ reductions were observed with the lower doses $(0.4$ and $0.2 \mathrm{mg} / \mathrm{d})$. The fact that the response to $0.4 \mathrm{mg}$ folic acid/d was $90 \%$ of the maximum response is important, because that is the amount of folic acid most often included as a component of multivitamin supplements. However, this effect is directly related to plasma Hcy concentrations, thus the improved folate status resulting from folic acid fortification is expected to attenuate the Hcy-lowering response to folic acid supplementation. Hcy lowering therapy with folate supplementation is simple, safe and inexpensive, and a recent meta-analysis of observational studies concluded that a $25 \%$ reduction in plasma Hcy concentration (similar to that observed with $0.8 \mathrm{mg}$ folic acid/d), was associated with modest decreases of $11-16 \%$ in the risk of ischemic heart disease and of 19-22\% in the risk of stroke (The Homocysteine Studies Collaboration, 2002). Several clinical trials are underway to assess the effect of folic acid on vascular outcomes.

Although many experimental studies have attempted to link folate depletion with DNA instability and/or mutagenesis, and great efforts have been made to corroborate an epidemiological inverse association between folate intake and colorectal cancer, a recent extensive review of the literature concludes that there is no convincing evidence for a chemopreventive effect of folate (Bollheimer et al. 2005). Few large epidemiological studies have explored the associations between nutrients, including folate, and Alzheimer's disease, and available data do not allow definitive conclusions on the protective power of folate intake (Luchsinger \& Mayeux, 2004). Similarly, evidences are inconsistent on the therapeutic effect of folic acid in depression (Taylor et al. 2004).

\section{Nut intake and homocysteinemia}

There is little information on the bioavailability of folate contained in nuts or on the effect of nut intake on serum folate. Two short-term feeding trials assessing the effects of diets enriched with nuts on the lipid profile of hypercholesterolemic subjects reported no effects of daily supplements of $73 \mathrm{~g}$ almonds (Jenkins et al. 2002) or 40-65 g walnuts (Ros et al. 2004) on plasma Hcy concentrations. The study subjects had normal baseline Hcy concentrations and, given the folate content of the nuts used (Table 2), no Hcy changes would have been expected. Another study used mixed nuts as part of a folaterich diet in patients with mild HHcy and showed a modest Hcy-lowering effect, which was similar to that of a $0.5 \mathrm{mg} / \mathrm{d}$ synthetic folic acid supplement (Pintó et al. 2005). Customary nut consumption may not reduce plasma Hcy by itself, but longterm intake of nuts as part of a healthy diet is likely to contribute to an adequate folate status.

\section{Minerals}

Excessive intake of some minerals (sodium) associated with suboptimal intake of other minerals (calcium, magnesium and potassium) is not uncommon today in individuals that have adopted the so-called Western dietary habits, characterized by increased animal fat consumption and decreased vegetable intake. An increasing body of evidence suggests that these dietary deviations in mineral intake may increase the risk of prevalent chronic conditions, such as cardiovascular disease, diabetes, cancer, osteoporosis and other illnesses (Cordain et al. 2005). Among common foodstuffs, nuts have a mineral profile that is one of the most beneficial for health.

\section{Calcium}

Calcium is an essential nutrient, quantitatively the most abundant of the body's minerals and a vital electrolyte. The body of a healthy adult contains between 1000 and $1400 \mathrm{~g}$ of calcium, $99 \%$ of which is located in the skeleton, while the remaining $1 \%$ is distributed among the different organs and 
tissues. This last fraction is of vital importance because it serves critical biological functions such as nerve conduction, muscle contraction, cell adhesiveness, mitosis and blood coagulation. The recommended daily allowance for calcium has long been $800 \mathrm{mg}$. Recognition of the many health benefits of calcium prompted increases in the DRI for calcium up to $1500 \mathrm{mg} / \mathrm{d}$ (Bryant et al. 1999). Inadequate intake of calcium is widespread and has been associated with several pathological conditions, such as osteoporosis, hypertension, obesity, diabetes and cancer development (Miller \& Anderson, 1999).

Although calcium-related research has focused particularly on osteoporosis (Nieves, 2005) and hypertension (Birkett, 1998), an increased intake of calcium also appears to have a significant cholesterol-lowering effect. A controlled clinical trial of calcium supplementation $(1 \mathrm{~g} / \mathrm{d})$ for 1 year was carried out in 223 postmenopausal women, and found a reduction of LDL cholesterol and an increase of HDL cholesterol that would be predicted to reduce cardiovascular event rates by $20-30 \%$ (Reid et al. 2002). This effect is possibly mediated by calcium enhancement of the faecal excretion of bile acids, cholesterol and fatty acids. Calcium also has an antilipogenic effect mediated by modulation of calcithrophic signalling pathways and adipocyte metabolism (Zemel, 2002). Although a recent meta-analysis did not show that calcium intake was linked to greater loss of body weight (Barr, 2003), there is increasing evidence that calcium (especially dairy calcium) may be related to a lower fat mass (St-Onge, 2005) and a reduced prevalence of the metabolic syndrome (Liu et al. 2005). Calcium intake may also have an anticarcinogenic effect (Baron et al. 1999).

There are not many foods that are calcium-rich. Among those with the highest content are pulses, milk and dairy products, small fish eaten whole (i.e. canned sardines) and nuts (Table 3). It is noteworthy that the calcium content of almonds more than doubles that of whole milk and is still higher than that of fortified milk $(140-160 \mathrm{mg} / 100 \mathrm{~g})$. Thus frequent nut intake certainly contributes to daily calcium needs. Calcium in nuts might also contribute to the consistent cholesterol-lowering effect of nuts.

\section{Magnesium}

Magnesium is the most abundant intracellular divalent cation. It is an essential cofactor for more than 300 enzymatic reactions and is critically involved in energy metabolism, glucose utilization, protein synthesis, fatty acid synthesis and breakdown, ATPase functions and virtually all hormonal reactions (Saris et al. 2000). The serum concentration of magnesium is tightly regulated within a narrow range of 0.7 to $1.1 \mathrm{mmol} / \mathrm{L}$ as a result of the efficiency of both the intestinal absorption and the renal conservation of magnesium. Because the magnesium content of the blood compartment is only $1 \%$ of whole body magnesium, plasma concentrations are not useful to assess marginal deficiencies of this mineral.

Magnesium deficiency is becoming common in Western populations due to decreased dietary intake and the use of diuretics. Conditions that may be associated with magnesium

Table 3. Calcium, magnesium, sodium and potassium content of nuts and other foods in $\mathrm{mg} / 100 \mathrm{~g}$ of edible portion

\begin{tabular}{|c|c|c|c|c|}
\hline Nuts & Calcium & Magnesium & Sodium & Potassium \\
\hline Almonds & 248 & 275 & 1 & 728 \\
\hline Brazil nuts & 160 & 376 & 3 & 659 \\
\hline Cashew nuts & 37 & 292 & 12 & 660 \\
\hline Hazel nuts & 114 & 163 & 0 & 680 \\
\hline Macadamia nuts & 85 & 130 & 5 & 368 \\
\hline Peanuts & 92 & 168 & 18 & 705 \\
\hline Pecans & 70 & 121 & 0 & 410 \\
\hline Pistachios & 107 & 121 & 1 & 1025 \\
\hline Walnuts & 98 & 158 & 2 & 441 \\
\hline \multicolumn{5}{|l|}{ Other foods } \\
\hline Apples (with skin) & 6 & 5 & 1 & 107 \\
\hline Asparagus (cooked) & 23 & 14 & 14 & 224 \\
\hline Bananas & 5 & 27 & 1 & 358 \\
\hline Beans (white, cooked) & 90 & 63 & 6 & 561 \\
\hline Beets (cooked) & 16 & 23 & 77 & 305 \\
\hline Broccoli (cooked) & 40 & 21 & 41 & 293 \\
\hline Cheese (cheddar) & 721 & 28 & 621 & 98 \\
\hline Chickpeas (cooked) & 49 & 48 & 7 & 291 \\
\hline Ham & 24 & 22 & 1304 & 287 \\
\hline Lettuce (romaine) & 33 & 14 & 8 & 247 \\
\hline Milk & 113 & 10 & 40 & 143 \\
\hline Pears & 9 & 7 & 1 & 119 \\
\hline Rice (white, cooked) & 10 & 38 & 1 & 35 \\
\hline Sardines (canned in oil) & 382 & 39 & 505 & 397 \\
\hline Spinach (cooked) & 136 & 87 & 70 & 466 \\
\hline Tomato & 10 & 11 & 5 & 237 \\
\hline Veal (cooked) & 22 & 26 & 87 & 325 \\
\hline Wheat bread & 72 & 86 & 527 & 252 \\
\hline
\end{tabular}

Source: US Department of Agriculture Nutrient Data Base at http://www.nal.usda.gov/fnic/ cgi-bin/nut_search.pl Accessed 29 December 2005 
deficiency include osteoporosis, hypertension, coronary heart disease, congestive heart failure, arrhythmia, diabetes mellitus, asthma, migraine headaches and pre-eclampsia; in many of these, magnesium supplementation has been beneficial in clinical studies, although the sounder evidences for a therapeutic use of magnesium are for pre-eclampsia and torsade des pointes, an infrequent but severe arrhythmia (Touyz, 2004).

The current DRI for magnesium is $400 \mathrm{mg} / \mathrm{d}$. Nuts contain more magnesium than any other common edible plants (Table 3). Given the inverse association between dietary magnesium and diabetes risk found in observational studies (Kao et al. 1999; Lopez-Ridaura et al. 2004), the magnesium content of nuts might be relevant to the reduced incidence of diabetes associated with frequent nut consumption (Jiang et al. 2002).

\section{Sodium and potassium}

From an evolutionary perspective, humans have experienced a drastic shift in salt intake from a diet low in sodium (approximately $0 \cdot 5-1 \mathrm{~g} / \mathrm{d})$ and high in potassium $(8-10 \mathrm{~g} / \mathrm{d})$ to an almost complete reverse pattern, largely as a result of the global availability of industrially processed foods (Cordain et al. 2005). Although the relationship between dietary salt, blood pressure and risk for cardiovascular disease has been debated for decades, a large body of epidemiological, clinical and experimental studies indicate a causal link between high salt intake and hypertension. Independent of the rise in blood pressure, dietary salt also increases cardiac left ventricular mass, arterial stiffness, the incidence of strokes and the severity of cardiac failure (Meneton et al. 2005). Conversely, there are persuasive evidences that increasing potassium intake reduces blood pressure and, independently of the blood pressure effect, decreases the incidence of stroke. In addition, an optimal potassium status is also beneficial for cardiac conduction, bone mineralization and insulin function, besides having a calcium-sparing effect in the kidney (He \& MacGregor, 2001).

The benefits of a low-sodium, high-potassium diet can be equated with those of a diet rich in vegetables and low in meat, dairy products and processed foods, the so-called DASH diet, which is also high in calcium and magnesium and is actually recommended for non-pharmacological treatment of elevated blood pressure (Appel et al. 2006), as well as for an overall good health (Hu. 2003). As shown in Table 3, the sodium and potassium content of nuts is one of the most beneficial of all common vegetable foods and fits perfectly with the above recommendations.

\section{Conclusions}

Current dietary recommendations include the maintenance of an adequate folate intake in order to lower plasma Hcy concentrations and inherent cardiovascular risk; a high intake of magnesium, along with calcium and potassium, to prevent bone demineralization and to lower blood pressure and the risk of cardiovascular diseases; and a low sodium intake to reduce blood pressure and improve the overall health status. These measures imply adopting a high-vegetable, low-saturated fat, low-cholesterol diet, and both the macronutrient and the micronutrient composition of nuts makes them an ideal component of such a healthy dietary pattern. The fact that nuts also contain significant amounts of phytosterols with intrinsic cholesterol-lowering properties is an additional reason to include them in the everyday diet. In proof of these assertions, a recent report of the PREDIMED study shows that, in comparison with a healthy low-fat diet, a Mediterranean diet that includes a daily serving of mixed nuts is associated with lower blood pressure, reduced blood glucose, improved insulin sensitivity, decreased LDL cholesterol and triglycerides, raised HDL cholesterol and reduced levels of circulating inflammatory markers in older individuals at high cardiovascular risk (Estruch et al. 2006).

\section{References}

Altmann SW, Davis HR Jr, Zhu LJ, Yao X, Hoos LM, Tetzloff G, et al. (2004) Niemann-Pick C1 like protein is critical for intestinal cholesterol absorption. Science 303, 1202-1204.

Andersson SW, Skinner J, Ellegard L, Welch AA, Bingham S, Mulligan A, Andersson H \& Khaw K-T (2004) Intake of dietary plant sterols is inversely related to serum cholesterol concentration in men and women in the EPIC Norfolk population: a cross-sectional study. Eur J Clin Nutr 58, 1378-1385.

Appel LJ, Brands MW, Daniels SR, Karanja N, Elmer PJ \& Sacks FM (2006) American Heart Association Dietary approaches to prevent and treat hypertension: a scientific statement from the American Heart Association. Hypertension 47, 296-308.

Bailey LB \& Berry RJ (2005) Folic acid supplementation and the occurrence of congenital heart defects, orofacial clefts, multiple births, and miscarriage. Am J Clin Nutr 81, suppl, $1213 \mathrm{~S}-1217 \mathrm{~S}$.

Baron JA, Beach M, Mandel JS, et al. (1999) Calcium supplements for the prevention of colorectal adenomas. Calcium Polyp Prevention Study Group. N Engl J Med 340, 101-107.

Barr SI (2003) Increased dairy product or calcium intake: is body weight or composition affected in humans? $J$ Nutr 133, $245 \mathrm{~S}-248 \mathrm{~S}$.

Berge KE, Tian H, Graf GA, Yu L, Grishin NV, Schultz J, Kwiterovich P, Shan B, Barnes R \& Hobbs HH (2000) Accumulation of dietary cholesterol in sitosterolemia caused by mutations in adjacent ABC transporters. Science 290, 1771-1775.

Birkett NJ (1998) Comments on a meta-analysis of the relation between dietary calcium intake and blood pressure. Am J Epidemiol 14, 223-228.

Bollheimer LC, Buettner R, Kullmann A \& Kullmann F (2005) Folate and its preventive potential in colorectal carcinogenesis. How strong is the biological and epidemiological evidence? Crit Rev Oncol Hematol 55, 13-36.

Bosner MS, Lange LG, Stenson WF \& Ostlund RE (1999) Percent cholesterol absorption in normal women and men quantified by dual stable isotopic tracers and negative ions mass spectrometry. J Lipid Res 40, 302-308.

Bryant RJ, Cadogan J \& Weaver CM (1999) The new dietary reference intakes for calcium: implications for osteoporosis. J Am Coll Nutr 18, 406S-412S.

Choi SW \& Mason JB (2000) Folate and carcinogenesis: An integrated scheme. J Nutr 130, 129-132.

Cordain L, Eaton SB, Sebastian A, Mann N, Lindeberg S, Watkins BA, O'Keefe JH \& Brand-Miller J (2005) Origins and evolution of the Western diet: health implications for the 21 st century. Am J Clin Nutr 81, 341-354.

Czeizel AE \& Dudas I (1992) Prevention of the first occurrence of neural-tube defects by periconceptional vitamin supplementation. $N$ Engl J Med 327, 1832-1835.

de Vries JHM, Jansen A, Kromhout D, van de Bovenkamp P, van Staveren WA, Mensink RP \& Katan MB (1997) The fatty 
acid and sterol content of food composites of middle-aged men in seven countries. J Food Comp Anal 19, 115-141.

Denke MA (1995) Lack of efficacy of low-dose sitostanol therapy as an adjunct to a cholesterol-lowering diet in men with moderate hypercholesterolemia. Am J Clin Nutr 61, 392-396.

Dietschy JM, Turley SD \& Spady DK (1993) Role of the liver in the maintenance of cholesterol and low density lipoprotein homeostasis in different animal species, including humans. J Lipid Res 34, $1637-1659$.

Estruch R, Martínez-González MA, Corella D, et al. (2006) Effects of a Mediterranean-style diet on cardiovascular risk factors. A randomized trial. Ann Intern Med, in press.

Food and Drug Administration (1996) Food standards: amendment of standards of identity for enriched grain products to require addition of folic acid. Final rule. 21 CFR Parts 136, 137, and 139. Fed Regist 61, 8781-8807.

Freisleben A, Schieberle P \& Rychlik M (2003) Specific and sensitive quantification of folate vitamers in foods by stable isotope dilution assays using high-performance liquid chromatography-tandem mass spectrometry. Anal Bioanal Chem 376, 149-156.

Griel AE \& Kris-Etherton PM (2006) Tree Nuts and the Lipid Profile: A Review of Clinical Studies. Br J Nutr 96, suppl. 2, S68-S78.

Hartmann MA (1998) Plant sterols and the membrane environment Trends Plant Sci 3, 170-175.

He FJ \& MacGregor GA (2001) Fortnightly review. Beneficial effects of potassium. Br Med J 323, 497-501.

Homocysteine Lowering Trialists' Collaboration (2005) Dose-dependent effects of folic acid on blood concentrations of homocysteine: a metaanalysis of the randomized trials. Am J Clin Nutr 82, $806-812$.

Hu FB (2003) Plant-based foods and prevention of cardiovascular disease: an overview. Am J Clin Nutr 78, suppl, 544S-551S

Jacques PF, Selhub J, Bostom AG, Wilson PWF \& Rosenberg IH (1999) The effect of folic acid fortification on plasma folate and total homocysteine concentrations. $N$ Engl J Med 340, $1449-1454$.

Jenkins DJ, Kendall CW, Marchie A, et al. (2002) Dose response of almonds on coronary heart disease risk factors: blood lipids, oxidized low-density lipoproteins, lipoprotein(a), homocysteine, and pulmonary nitric oxide: a randomized, controlled, crossover trial. Circulation 106, 1327-1332.

Jiang R, Manson JE, Stampfer MJ, Liu S, Willett WC \& Hu FB (2002) Nut and peanut butter consumption and risk of type 2 diabetes in women. JAMA 288, 2554-2560.

Jones PJH, MacDougall DE, Nitanios FY \& Vanstone CA (1997) Dietary phytosterols as cholesterol-lowering agents in humans. Can J Physiol Pharmacol 75, 217-227.

Kao WH, Folsom AR, Nieto FJ, Mo JP, Watson RL \& Brancati FL (1999) Serum and dietary magnesium and the risk for type 2 diabetes mellitus: the Atherosclerosis Risk in Communities Study. Arch Intern Med 15, 2151-2159.

Katan MB, Grundy SM, Jones P, Law M, Miettinen T \& Paoletti R (2003) Efficay and safety of plant stanols and sterols in the management of blood cholesterol levels. Mayo Clinic Proc $\mathbf{7 8}$, 965-978.

Kesäniemi YA \& Miettinen TA (1987) Cholesterol absorption efficiency regulates plasma cholesterol levels in the Finnish population. Eur J Clin Invest 17, 391-395.

Kim YI (1999) Folate and carcinogenesis: Evidence, mechanisms, and implications. J Nutr Biochem 10, 66-88.

Law M (2000) Plant sterol and stanol margarines and health. BMJ 320, 861-864.

Lee MH, Lu K, Hazard S, Yu H, et al. (2001) Identification of a gene, ABCG5, important in the regulation of dietary cholesterol absorption. Nat Genet 27, 79-83.

Liu S, Song Y, Ford ES, Manson JAE, Buring JE \& Ridker PM (2005) Dietary calcium, vitamin D, and the prevalence of metabolic syndrome in middle-aged and older U.S. women. Diabetes Care 28, 2926-2932.

Lopez-Ridaura R, Willett WC, Rimm EB, Liu S, Stampfer MJ, Manson JE \& Hu FB (2004) Magnesium intake and risk of type 2 diabetes in men and women. Diabetes Care 27, 134-140.

Luchsinger JA \& Mayeux R (2004) Dietary factors and Alzheimer's disease. Lancet Neurol 3, 79-587.

Mason JB (2003) Biomarkers of nutrient exposure and status in onecarbon (methyl) metabolism. J Nutr 133, Suppl 3, 941S-947S.

McNulty H \& Pentieva K (2004) Folate bioavailability. Proc Nutr Soc 63, 529-536.

Meneton P, Jeunemaitre X, de Wardener HE \& MacGregor GA (2005) Links between dietary salt intake, renal salt handling, blood pressure, and cardiovascular diseases. Physiol Rev 85, 679-715.

Miller GD \& Anderson JJ (1999) The role of calcium in prevention of chronic diseases. J Am Coll Nutr 18, 371S-372S.

Mooijaart SP, Gussekloo J, Frölich M, Jolles J, Stott DJ, Westendorp RGJ \& de Craen AJM (2005) Homocysteine, vitamin B-12, and folic acid and the risk of cognitive decline in old age: the Leiden 85-Plus Study. Am J Clin Nutr 82, 866-871.

Moreau RA, Whitakerb BD \& Hicksa KB (2002) Phytosterols, phytostanols, and their conjugates in foods: structural diversity, quantitative analysis, and health-promoting uses. Progr Lipid Res 41, 457-500.

MRC Vitamin Study Research Group (1991) Prevention of neural tube defects: results of the Medical Research Council Vitamin Study. Lancet 338, 131-137.

Nieves JW (2005) Osteoporosis: the role of micronutrients. Am J Clin Nutr 81, 1232S-1239S.

Northfield TC \& Hoffmann AF (1975) Biliary lipid output during three meals and an overnight fast. I. Relationship to bile acid pool size and cholesterol saturation in gallstone and control subjects. Gut 16, 1-11.

O'Neill FH, Sanders TAB \& Thompson GR (2005) Comparison of efficacy of plant stanol ester and sterol ester: short-term and longer-term studies. Am J Cardiol 96, suppl, 29D-36D.

Ostlund RE Jr (2002) Phytosterols in human nutrition. Annu Rev Nutr 22, 533-549.

Ostlund RE Jr, Racette SB, Okeke A \& Stenson WF (2002) Phytosterols that are naturally present in commercial corn oil significantly reduce cholesterol absorption in humans. Am J Clin Nutr 75, 1000-1004.

Ostlund RE Jr, Racette SB \& Stenson WF (2003) Inhibition of cholesterol absorption by phytosterol-replete wheat germ compared with phytosterol-depleted wheat germ. Am J Clin Nutr 77, 1385-1389.

Ostlund RE Jr (2004) Phytosterols and cholesterol metabolism. Curr Opin Lipidol 15, 37-41.

Phillips KM, Ruggio DM \& Ashraf-Khorassani M (2005) Phytosterol composition of nuts and seeds commonly consumed in the United States. J Agric Food Chem 53, 9436-9445.

Piironen V, Lindsay DG, Miettinen TA, Toivo J \& Lampi A-M (2000) Plant sterols: biosynthesis, biological function and their importance to human nutrition. $J$ Sci Food Agric 80, 939-966.

Pintó X, Vilaseca MA, Balcells S, Artuch R, Corbella E, Meco JF, Vila R, Pujol R \& Grinberg D (2005) A folate-rich diet is as effective as folic acid supplements in decreasing plasma homocysteine concentrations. Int J Med Sci 2, 58-63.

Plat J \& Mensink RP (2005) Plant stanol and sterol esters in the control of blood cholesterol levels: mechanism and safety aspects. Am J Cardiol 96, suppl, 15D-22D.

Prins ND, den Heijer T, Hofman A, Koudstaal PJ, Jolles J, Clarke R \& Breteler MM (2002) Rotterdam Scan Study Homocysteine and cognitive function in the elderly. The Rotterdam Study. Neurology 59, $1375-1380$.

Reid IR, Mason B, Horne A, Ames R, Clearwater J, Bava U, Orr-Walker B, Wu F, Evans MC \& Gamble GD (2002) Effects of calcium supplementation on serum lipid concentrations in normal older women: a randomized controlled trial. Am J Med 112, 343-347. 
Ros E (2000) Intestinal absorption of triglyceride and cholesterol. Dietary and pharmacological inhibition to reduce cardiovascular risk. Atherosclerosis 151, 357-379.

Ros E, Núñez I, Pérez-Heras A, Serra M, Gilabert R, Casals E \& Deulofeu R (2004) A walnut diet improves endothelial function in hypercholesterolemic subjects. Circulation 109, 1609-1614.

Said HM (2004) Recent advances in carrier-mediated intestinal absorption of water-soluble vitamins. Annu Rev Physiol 66, 419-446.

Sanderson P, McNulty H, Mastroiacovo P, McDowell IFW, Melse-Boonstra A, Finglas PM \& Gregory JF III (2003) Folate bioavailability: UK Food Standards Agency workshop report. Br J Nutr 90, 473-479.

Saris NE, Mervaala E, Karppanen H, Khawaja JA \& Lewenstam A (2000) Magnesium. An update on physiological, clinical and analytical aspects. Clin Chim Acta 29, 1-26.

Sehayek E (2004) Genetic regulation of cholesterol absorption and plasma plant sterol levels: commonalities and differences. J Lipid Res 44, 2030-2038.

Sehayek E, Nath C, Heinemann T, McGee M, Seidman CE, Samuel P \& Breslow JL (1998) U-shape relationship between change in dietary cholesterol absorption and plasma lipoprotein responsiveness and evidence for extreme interindividual variation in dietary cholesterol absorption in humans. J Lipid Res 39, 2415-2422.

Selhub J, Jacques PF, Wilson PW, Rush D \& Rosenberg IH (1993) Vitamin status and intake as primary determinants of homocysteinemia in an elderly population. JAMA 270, 2693-2698.

Seshadri S, Beiser A, Selhub J, Jacques PF, Rosenberg IH, D'Agostino RB, Wilson PW \& Wolf PA (2002) Plasma homocysteine as a risk factor for dementia and Alzheimer's disease. $N$ Engl J Med 346, 476-483.

Shane B (1995) Folate chemistry and metabolism. In Folate in Health and Disease, [LB Bailey, editor]. New York, NY: Marcel Dekker pp. $1-22$.

Shin MJ, Lee JH, Jang Y, Lee-Kim YC, Park E, Kim KM, Chung BC \& Chung N (2005) Micellar phytosterols effectively reduce cholesterol absorption at low doses. Ann Nutr Metab 49, 346-351.

St-Onge MP (2005) Dietary fats, teas, dairy, and nuts: potential functional foods for weight control? Am J Clin Nutr 81, 7-15.

Stover PJ (2004) Physiology of folate and vitamin B12 in health and disease. Nutr Rev 62, S3-S12.

Strain JJ, Dowey L, Ward M, Pentieva K \& McNulty H (2004) B-vitamins, homocysteine metabolism and CVD. Proc Nutr Soc 63, 597-603.
Sudhop T \& von Bergmann K (2002) Cholesterol absorption inhibitors for the treatment of hypercholesterolaemia. Drugs 62, 2333-2347.

Taylor MJ, Carney SM, Goodwin GM \& Geddes JR (2004) Folate for depressive disorders: systematic review and meta-analysis of randomized controlled trials. J Psychopharmacol 18, $251-256$.

The Homocysteine Studies Collaboration (2002) Homocysteine and risk of ischemic heart disease and stroke: a meta-analysis. JAMA 288, 2015-2022.

Thompson GR \& Grundy SM (2005) History and development of plant sterol and stanol esters for cholesterol-lowering purposes. Am J Cardiol 96, suppl, 3D-9D.

Touyz RM (2004) Magnesium in clinical medicine. Front Biosci 9 , $1278-1293$.

Turley SD \& Dietschy JM (2003) Sterol absorption by the small intestine. Curr Opin Lipidol 14, 233-240.

Vahouny GV, Borja CR \& Treadwell CR (1964) Absorption and esterification of micellar free and esterified cholesterol. Arch Biochem Biophys 106, 440-446.

Vanstone CA, Raeini-Sarjaz M, Parsons WE \& Jones PJ (2002) Unesterified plant sterols and stanols lower LDL-cholesterol concentrations in hypercholesterolemic persons. Am J Clin Nutr 76, $1272-1278$.

Vaskonen T (2003) Dietary minerals and modification of cardiovascular risk factors. $J$ Nutr Biochem 14, 492-506.

von Bergmann K, Sudhop T \& Lütjohann D (2005) Cholesterol and plant sterol absorption: recent insights. Am J Cardiol 96, suppl, 10D-14D.

Vuoristo M \& Miettinen TA (1985) Increased biliary lipid secretion in coeliac disease. Gastroenterology 88, 134-142.

Vuoristo M \& Miettinen TA (1994) Absorption, metabolism, and serum concentrations of cholesterol in vegetarians: effects of cholesterol feeding. Am J Clin Nutr 59, 1325-1331.

Wald DS, Law M \& Morris JK (2002) Homocysteine and cardiovascular disease: evidence on causality from a meta-analysis. BMJ 325, $1-7$.

Welch GN \& Loscalzo J (1998) Homocysteine and atherothrombosis. $N$ Engl J Med 338, 1042-1050.

Zemel MB (2002) Regulation of adiposity and obesity risk by dietary calcium: mechanisms and implications. J Am Coll Nutr 21, $146 \mathrm{~S}-151 \mathrm{~S}$. 